\title{
Motivation of the personnel of hi-tech productions
}

\author{
N.V. Trifonova ${ }^{1, *}$, and O.A. Shvetsova ${ }^{1, *}$ \\ ${ }^{1}$ Saint-Petersburg State University of Economics, Saint-Petersburg, Russia
}

\begin{abstract}
In work the actual problem of motivation of representative group of highly qualified specialists of the domestic knowledge-intensive enterprises is considered. Approaches to research of motivators of innovative processes for problems of modernization of a domestic production are studied. Practice of use of innovative instruments of motivation at the Russian industrial enterprises is studied. The perspective of an integrated approach to human resource management of hi-tech productions, including competencebased approach to preparation innovative the managing director of employees is investigated. Authors have offered new approaches to formation of the steady motivational mechanism of key personnel of the domestic industrial enterprises.
\end{abstract}

\section{Introduction}

Periodic changes of market conditions, extensive national modernization of hi-tech sector on the basis of indicative management and development of professional competences of the experts demanded for transformation and a producing knowledge, technologies, innovations are the main factorial reasons for structural shifts in national economy at a present historical stage. Development of technological and not technological field of the Russian economy has cyclic character. Among the reasons of structural shifts of sectors of national economy there are exogenous and endogenous factors which are shown on micro and the macrolevel of national economic system.

Start of accelerating process of structural shifts in innova-tive and hi-tech sectors of economy it is usually connected with functional business cycles (D. Kitchena, S. Kuznetsa), and cycles of development of $\mathrm{N}$. Kondratyev. It is considered to be that the ascending and descending wave of a macroeco-nomic cycle influences intensity of structural shifts in sectors of economy and is followed by change of a priority of the leading innovative technologies. In the descending trajectory of a macroeconomic cycle elements of structure of hi-tech sector of economy are not so steady, are characterized by reduction of innovative and investment appeal of a manufacturing sector, transformation of production demand in the resource markets. Elements of institutional structure of the market of a manpower in various sectors of economy connected with technologies in the field of innovations are subject to influence of macroeconomic cycles. It is known that economic crises do essential harm to structure of production, to the economic relations, a shape of employment of key personnel is got out of stability. The hi-tech sector of economy as a key element of national economy passes a stage of transformational shift as a result of crisis of the relations with foreign investors in Russia, decrease in production of high technologies, changes of forms of the competition of involvement of employees now.

Expansion of use of industrial and system innovations in sectors of economy involves creation of specialized workplaces with higher labor productivity level, strengthening of horizontal integration of structure of production and the regional markets. Result of formation of hi-tech sector of economy in regions of the country are strong industrial clusters which as points of economic growth become the generator of innovative demand, a source of development of the professional market of labor and models of social partnership of territories. Interaction of economic factors of economic growth creates unstable dynamics, cyclic dynamics of structural transformations of sectors of economy and the market of labor, causing change of popular vocational groups of employees that demands new effective forms of motivation of personnel.

\section{Approaches to personnel' motivation}

In the knowledge-intensive branches of domestic economy it is possible to consider two approaches to motivation of a key human resource. The classical approach based on the administrative technologies corresponding to an era of "industrial economy" and realized within industrial technological way. Innovative (or knowledge-based) the approach focused on the enterprises functioning in more modern technological way (the economy based on knowledge). Features of innovative administrative technologies, and also advantages and restrictions of their introduction in activity of the modern innovative enterprises are defined by heads of data of the organizations.

In M. A. Benediktov's works, A.A. Bureeva, $[1,2]$ is offered author's interpretation of concept and essence of innovative processes as key competence of the knowledge-intensive productions. As innovative process these authors consider process of transformation of 
scientific knowledge in an innovation which can be described as a consecutive chain of events in the course of which the innovation "grows" from scientific ideas in concrete new products, technologies or services and extends at applied use.

\section{Specifics of human resource management of the hi-tech enterprises}

It is possible to allocate the following signs of hi-tech productions:

- Complex high-tech processes.

- Knowledge-intensive products.

- Essential share of costs of research and development.

- Highly qualified specialists with specific key competences.

- Constant staff shortage of qualified personnel.

- High percent of export production in the general volume of the made production.

- Stable foreign communications and technological cooperation.

- The centralized corporate training centers of preparation of personnel.

- Qualitative investment appeal and high dynamism of production [3, 4].

Among branches of hi-tech sector of the Russian economy there are following cluster associations: nuclear energy industry, communication, telecommunications, chemistry and petrochemistry, pharmaceutical industry, power, electronics, aircraft industry, rocket production, defensive industry [3].

In modern economic and political conditions the knowledge-intensive enterprises more than ever demand the latest domestic and foreign the practician in management of a human resource (Table 1).

Table 1. Types of management of human resources in hightech industries of economy.

\begin{tabular}{|c|c|}
\hline $\begin{array}{l}\text { The management focused on result } \\
\text { - delegation of zones of } \\
\text { responsibility } \\
\text { c modeling of situations of } \\
\text { cooperation of employees }\end{array}$ & $\begin{array}{l}\text { Management on bases of } \\
\text { collective participation in the } \\
\text { general process } \\
\text { - universal quality control of } \\
\text { production } \\
\text { - interest of the worker and his } \\
\text { development in innovative } \\
\text { activity, including through } \\
\text { educational process and process } \\
\text { of mentoring }\end{array}$ \\
\hline $\begin{array}{l}\text { Management by means of } \\
\text { motivational technologies } \\
\text { - rational model of remuneration } \\
\text { - motivational model of self- } \\
\text { realization } \\
\text { - motivational model of } \\
\text { participation in results of the } \\
\text { organization in general }\end{array}$ & $\begin{array}{l}\text { Frame management with active } \\
\text { involvement of all employees } \\
\text { - encouragement of an initiative } \\
\text { of employees } \\
\text { - development skills of } \\
\text { communicative of } \\
\text { employees }\end{array}$ \\
\hline $\begin{array}{l}\text { Management on the basis of } \\
\text { business } \\
\text { - the competitive atmosphere in } \\
\text { group of employees } \\
\text { - implementation of joint projects } \\
\text { by workers }\end{array}$ & \\
\hline
\end{tabular}

Formation and development of professional competences of staff of the hi-tech organizations can be presented in the form of three "stages":

"The growing experts".

"The frozen experts".

"The experts moving down" [5].

The assessment of requirements and planning of professional competences of personnel of the hi-tech enterprises allows to determine problems of strategic personnel capacity of the enterprise in general (Fig. 1).

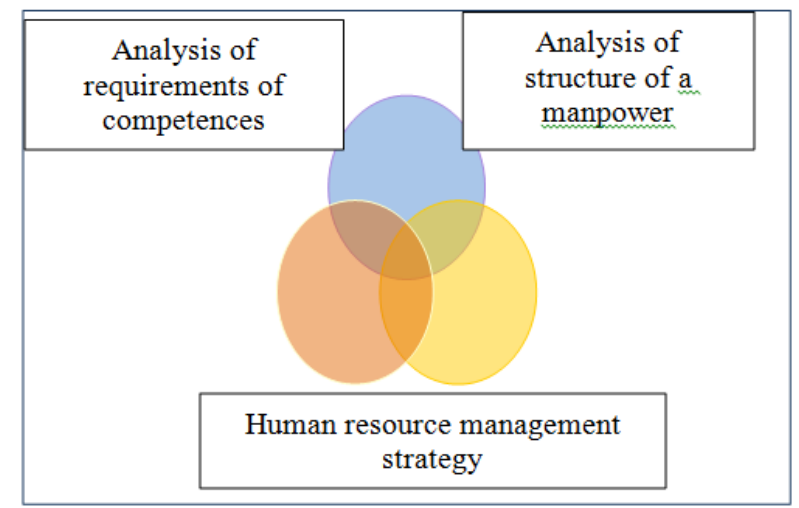

Fig. 1. Determination of professional competences of key staff of the hi-tech enterprises.

On the basis of the analysis of activity of a number of the domestic enterprises it is possible to reveal restrictions of development of professional competences of staff of the companies of high-tech industries of economy:

- Weak level of development of knowledge and skills of linear heads

- Idle ways of development and adoption of administrative decisions

- Insufficiently developed level of creative skills of employees and team building

- Absence of motivation of employees to use of innovations

- Rivalry of employees and conflict behavior in group, high degree of individualism

- Inefficient informal relations of employees, lack of effective system of communication.

It is possible to give practice of use of the concept of the Japanese management in management of the key staff of the enterprises of nuclear energy industry as an example of work with restrictions of development of professional competences (Rosatom State corporation, JSC TVEL, JSC SHK) [6]:

- Flexible management of experts, regulation of procedures

- Adaptive mechanisms of material remuneration

- Reduction of a share of administrative resources in the total number of employees

- Orientation to design and target groups and team building

- Realization of continuous training in system of corporate training 
- Universal participation in quality of production and division of responsibility for quality of the received results.

In modern difficult economic conditions many domestic production companies actively financially support problems of production. However isn't enough for formation of fund of material remuneration of personnel of means. This factor increases often the level of a demotivating of employees, and it creates a certain threat: level of loyalty of key personnel to the company decreases, manifestation of deviant behavior, and also increases of coefficient of fluidity of personnel is possible. The company will lose an opportunity to develop and form competitive strategy. The employees however demotivated, but built in innovative process represent strategic (often implicit) threat: at the crisis moments such personnel won't show loyalty to the company, don't create risk - the focused model of innovative search or at all to leave firm in search of new opportunities (obviously in the competing systems).

Often, the companies with effective personnel management try to replace material motivation with nonmaterial instruments of influence, thereby showing the interest in satisfaction of requirements and interests of employees, and the demotivating of the employees who are innovatively focused and professionally taken place is destructive.

In personnel management of the hi-tech enterprises treats non-material ways of impact on the worker:

1. Paternalism - concerning the worker is shown some guardianship, he feels care and attention from the management. The employee is involved in various actions for management of the organization, give loyal opportunities for personal and informal contact, provide broad delegation of powers and division of zones of responsibility, system of side benefits for elimination of the conflicts and intensity in the atmosphere of collective.

2. Patriotism - formation of mission of the enterprise which is congenial to workers it is actual and adequate to modern realities, is achievable.

The motivation of patriotism can be realized as means in the internal environment of the organization, and through the existing strategy and policy of regional representatives, branches and the states in general.

3. Organizational incentives - stimulation by the importance, conditions and the organization of work.

The way of impact on motives of employees allowing to have satisfaction from work performance process follows from the content of the work: it is necessary to organize work of personnel so that it coincided with their natural incentive incentives. Some experts call this process a form of organizational ergonomics.

4. The participation and participation in management - this form of motivation offers involvement of the employee to management, use of open type of information culture, that is granting large volume of administrative information in open access through corporate databases, a vote in decision-making, individual share in profit and the capital of the organization, a possibility of receiving significant percent from order cost when attracting him in the organization.

\section{Model of personnel' motivation of the knowledge-intensive productions}

In the field of economy and sociology of management and practical experience of the innovative companies 4 stages of process of use of innovative technologies of stimulation of employees in the organizations allow to present research of works.

1 stage. Formation and submission of the specialized program of motivation of personnel with the indication of feature of motivational mechanisms for each group of personnel.

2 stage. Definition of zones of responsibility of each linear head for this or that mechanism of motivation in the divisions.

3 stage. Creation of the working group of representatives of department of personnel and specialists of production divisions for the purpose of performance of control over results of works.

4 stage. Analysis of instruments of motivation, their assessment, definition strong and weaknesses of the mechanism of development and realization of innovations, introduction of measures for their further development.

Authors offer innovative tools of system of motivation and stimulation of key employees of hi-tech productions (Fig. 2).

\begin{tabular}{|c|c|c|}
\hline $\begin{array}{lr}\text { Motivation } & \text { of } \\
\text { personnel } & \text { by } \\
\text { means } & \text { of } \\
\text { introduction } & \text { of } \\
\text { technologies of a } \\
\text { goal-setting }\end{array}$ & $\begin{array}{l}\text { Motivation of } \\
\text { personnel by } \\
\text { means of } \\
\text { modern } \\
\text { compensation } \\
\text { systems } \\
\end{array}$ & $\begin{array}{l}\text { Motivation of personnel } \\
\text { by means of } \\
\text { introduction } \\
\text { technology of team } \\
\text { building }\end{array}$ \\
\hline $\begin{array}{l}\text { Motivation of } \\
\text { personnel through } \\
\text { integration into } \\
\text { corporate culture }\end{array}$ & $\begin{array}{l}\text { Innovative } \\
\text { technologies } \\
\text { of motivation } \\
\text { of personnel } \\
\text { in the hi-tech } \\
\text { companies }\end{array}$ & $\begin{array}{l}\text { Motivation of personnel } \\
\text { through delegation of } \\
\text { powers }\end{array}$ \\
\hline $\begin{array}{lr}\text { Motivation } & \text { of } \\
\text { personnel } & \text { by } \\
\text { means } & \text { of } \\
\text { introduction } & \text { of } \\
\text { technologies of an } \\
\text { assessment } \\
\text { employees }\end{array}$ & $\begin{array}{l}\text { Motivation of } \\
\text { personnel } \\
\text { through } \\
\text { introduction } \\
\text { of } \\
\text { technologies } \\
\text { of } \\
\text { preparation } \\
\text { and } \\
\text { development } \\
\text { of employees }\end{array}$ & $\begin{array}{l}\text { Motivation of personnel } \\
\text { through use of } \\
\text { technologies of } \\
\text { management of career }\end{array}$ \\
\hline
\end{tabular}

Fig. 2. Model of system of motivation of personnel in the hitech companies: innovative approach [6].

The offered model - not just arithmetic sum of components of administrative technologies:

1. Mechanical addition (decrease) any of elements of this system isn't capable to lead to adequate change to the consolidated motivational potential. Motivational potential is a result of synergetic interaction of these tools.

2. Identification of requirements and strengthening of motivational potential. Integrity of the specified model 
promotes development of negative consequences, namely the known loss by elements of system of sovereignty. Their work within system paints elements the new motivating quality, releases also increases their primary motivational potential.

3. The "initial" motivational resource of elements of model which is originally present at them as an opportunity thanks to the processes arising in system is transformed to reality.

Participation in administrative processes can get various formats, in a varying degree, proving the efficiency - from rendering preliminary consultations with representatives of employees before acceptance of administrative signals, partnership in the solution of the arising problem signals by means of creation of circles of quality, independent groups before execution by representative bodies of employees (councils, committees, the commissions) of concrete administrative functions.

For management efficiency increase, it is necessary to meet the following conditions:

- the operating employee and employeesperformers have to have enough time for performance of this function (in crisis situations similar practice is inexpedient);

- possible benefits from participation in management have to cover cost (for example, the time period which is taken away on participation in management shouldn't exceed time allowed for the main working operations);

- workers show incentives in participation in management;

- competences and qualification of employees have to allow them to take part in management;

- participants of working procedures have to possess competences to interaction within primary informal structures that gives them an opportunity of primary approbation of ideas and uncommon decisions;

- the parties shouldn't treat participation in management as to threat (for example, workers are capable to perceive indications of the management as perhaps dangerous or the head can consider that participation in management doesn't correspond to his status);

- application of practice of participation in management has to be presented as a freedom of choice of working tasks of group (each division has no right to make the decision breaking policy of the company).

Participation of collective in management and having profits by the enterprise as a strategic form of development is accepted by an increasing number business of structures. One of the reasons of a demand of the specified method is the economic aspect of his use: to raise funds "internal resources" (having sold shares of the organization to workers) more favorably and less risky, than from outside.

This participation can be realized at several levels. At the level of a concrete workplace or the working group administrative decisions or improvement suggestions belong to specifications of labor process, communication with colleagues, to labor conditions, daily questions of human resource management; at the level of the organization - this participation of personnel in the solution of questions of a strategic reference point (a production goal-setting, investments, distribution of the income, organizational structure). In addition, these questions concern the concrete labor relations in a situation "the worker - the employer" (compensation, holidays, working hours, social guarantees). At the following level the personnel participate in relationship between the enterprise and labor union which have branch and interindustry character.

Formation of potential of key personnel - planning of a career ladder, work with a personnel reserve, corporate training, mentoring, mentoring, coaching, tutoring, rotation, increase and other.

The specified way of motivation is based on needs for self-expression and on aspiration of each employee to develop, increasing greatly knowledge, skills and experience. When using beneficial influence not only on the level of satisfaction with work of personnel, but also on enhancement of a human resource of own enterprise through formation of competences appears the management of the organization of this type of stimulation. Transformation of administrative processes under the influence of the market relations means prompt dynamics of change of requirements to qualitative parameters of a labor resource. Sharks of business (especially industrial productions) increase investments into preparation of personnel as external market conditions and system of personnel training correspond to requirements of hi-tech productions less. In this situation many enterprises go for increase in investments in development of personnel and consider this action the main competitive factor.

Formation of key competences of staff of the company forms loyalty of personnel which, in turn, possesses steadier abilities and reasonable motivation to performance of tasks. It is natural that it leads to growth of productivity, and respectively, to increase in value of human resources of the organization.

In the social environment of the organization psychological influence on employees can be used, for example, it can be carried out as in a positive form information transfer about the expert's merits, an assessment of the head and colleagues, recognition of merits; and in negative - censure, punishment, work loss threat.

The specified way of motivation significantly depends on the identity of the head who exercises influence and control.

It is possible to define the most widespread methods of psychological influence on personnel of the organization:

- belief - the impact on other person or a group of persons proved with application of the argument aiming at correction of their judgment, the relation, intention or the decision, for example, at statement of the purposes; 
- suggestion - reasonable, but without application of the argument the impact on the person or a group of persons aiming at correction of their state, understanding something and tendency to certain working acts, for example, in situations when the manager carries out actions, unpopular among the employees: reduction of number of personnel, cancellation of additional guarantees, changes in process of training and development;

- self-advance - representation of the principles, the purposes, guarantees and presentation of confirmations of the competence and experience for obtaining personal benefits; for example, the middle manager for increase of the personal authority at negotiation with new interesting clients for obtaining advantages on elections can undertake such behavior, at appointment to the post;

- infection - broadcast of the state or relation to other worker or a group of persons who feel the transferred state or the relation; the state is capable to be broadcast as involuntarily, and it is operated, to get accustomed when forming lines of corporate culture, for example, of public actions, sports rest, introduction of corporate style in clothes;

- awakening of an impulse to imitation - skill to render aspiration to resemble itself; for example, this method can be applicable the charismatic leader with use of an image of the successful company;

- the request - the address to the colleague with a request to meet requirements or desires of the initiator of influence, for example: the aspiration of the head to make subordinated by the participant of a situation leads to formation at the subordinated feeling of the importance; often heads of the manufacturing and knowledgeintensive enterprises put forward requests to satisfy a certain project, to look for resources;

- coercion (in the conditions of rigid temporary deficiency within design decisions and dynamics) - threat of use of the directive abilities by the initiator with the purpose to achieve from the addressee of desirable behavior; for example, the most often specified way is based on understanding of the importance of safety, the head specifies by the subordinate that in his forces to deprive of them all rights; all this exerts strong impact on personnel;

- manipulation - the hidden management of the addressee in participation in experiences, decision-making, performance of the actions necessary for the personal purposes of the initiator, that is head, for example: the desire of the worker direct difficult production site can stimulate a long time him on the organization of works of other experts without additional material incentives.

\section{Conclusion}

In the innovative and technological environment demand for the creative and creative competences of qualified personnel considering interpersonal communicative abilities and an active exchange of key information amplifies and becomes complicated on the structure. Analytical, search and research competences of the expert of hi-tech production become the most important element of development of professional competences by the purpose of management of corporate knowledge and innovations. Information, knowledge, skills, talents of the hired worker are transformed to the leading factor of formation of competitive advantages in labor market and the labor relations, increasing greatly the value of applied technical skills and innovative culture. The highly qualified specialist as the carrier of knowledge and innovative culture, socially oriented values becomes a source of development of the innovative technologies and new organizational forms of the knowledgeintensive production capable to stimulate introduction of various technologies of adaptation of the market of labor to competence-based requirements of real sector of economy. Professional and corporate values of the expert reflect a level of development of culture, cognitive abilities, talent and socially oriented requirements, are institutionalized by the hired expert and the employer during the period of joint activity that leads to change of structure of social and economic development of production territories, formation new highly specialized, the innovative of the grocery markets and services.

Thus, in modern economic conditions the professional specialist of the enterprises of the knowledge-intensive branches of economy is considered not only as the performer of production tasks, he becomes the active and interested participant of innovative activity of the organization. Participation in management and creation of an innovative product is an element of the system of participation of staff of the enterprise in general including also participation in profits and participation in property. At the same time, participation in profits and property belongs to system of material remuneration, and participation in management - to external (creation of the corresponding conditions from the management) and internal motivation of the non-material stimulating character (development in key personnel of feeling of self-determination and competence).

\section{References}

1. S.E. Brewers, L.S. Tarasevich, A.V. Butukhanov, A.I. Mayzel, R. R. Manukyan, I.S. Brewers, A.I. Pogorletsky, N.V. Trifonova, T.G. Tumarov, M.Z. Epstein, Inter-national management (St. Petersburg, 2008) 
2. T.A. Khudyakova, A.V. Shmidt, The 26th International Business Information Management Association Conference, 1626-1634 (2015)

3. V.M. Kutuzov, S.O. Shaposhnikov, O.A. Shvetsova, Planning and Ensuring Training for an Industrial and Economic Complex of the Region, 125-136 (2015)

4. V.V. Olkhovsky, Methods and sources of formation of intangible assets of the organization, New in economy and management (MAX. Press, Moscow, 2006)

5. N.V. Trifonova, Questions of new economy, 2, 7173 (2009)

6. O.A. Shvetsova, News of "LETI", 3, 75-85 (2015)

7. O.A. Shvetsova, The 26th International Business Information Management Association Conference, 1606-1618 (2015)

8. GOST $R$ 56407-2015, Lean production: main methods and instruments.

9. T.A. Khudyakova, A.V. Shmidt, The 26th International Business Information Management Association Conference, 1607-1611 (2015)

10. E. Mach, Erkenntniss und Irrtum (German, Reidel Publ., 1976)

11. R. Mayer, M. Painter, C. Menzel, B. Perakath, P. deWitte, T. Blinn, Knowledge Based Systems Publ., (1995)
12. National Institute of Standards and Technology, Integration definition for function modeling (IDEF0) (1993)

13. Ching-Hong Tsai, How-Jen Luo, Feng-Jian Wang, 11th IEEE International Workshop on Future Trends of Distributed Computing Systems (2007). DOI: 10.1109/FTDCS.2007.17.

14. R. Braun, IEEE 17th Conference on Business Informatics (CBI) (2015). DOI: 10.1109/CBI.2015.41.

15. S. Yamasathien, Fourth International Conference on Digital Information and Communication Technology and it's Applications (DICTAP) (2014) DOI: 10.1109/DICTAP.2014.6821684.

16. M. Chinosi, A. Trombetta, IEEE Conference on Commerce and Enterprise Computing (2009) DOI: 10.1109/CEC.2009.48.

17. A.H. Maslow, Psychological Review, 50(4), 370$396(1943)$

18. A.H. Maslow, Motivation and personality (Harper \& Row Publ., 1954)

19. J.O. Long, ITIL 2011 At a Glance (Springer New York Publ., 2012). DOI: 10.1007/978-1-4614-38977.

20. A Guide to the Project Management Body of Knowledge (PMBOK Guide) (Project Management Institute Publ., 2013)

21. http://www.metodolog.ru. 